\title{
COMMENTARY
}

\section{A novel effect of eicosapentaenoic acid: improved diaphragm strength in endotoxemia}

\author{
Philip C Calder* \\ See related research by Supinski et al., http://ccforum.com/content/14/2/R35
}

\begin{abstract}
Respiratory muscle weakness is commonplace in critically ill patients, impairing the ability of those patients to breath, prolonging the need for ventilatory support, and increasing the likelihood of respiratory failure when that support is removed. Infections and endotoxemia reduce respiratory muscle strength, probably acting through several mechanisms. It is reported that the omega-3 fatty acid eicosapentaenoic acid (EPA) attenuates the loss in diaphragm specific force generation (that is, diaphragm strength) induced by bacterial endotoxin treatment in rats. EPA is found in fish oils. EPA reduces calpain activation, suggesting a specific effect on this proteolytic pathway. It will be important to identify whether this effect occurs in patients receiving EPA.
\end{abstract}

Respiratory muscle weakness is commonplace in critically ill patients, impairing the ability of those patients to breath, prolonging the need for ventilatory support, and increasing the likelihood of respiratory failure when that support is removed. Infections and endotoxemia reduce respiratory muscle strength, probably acting through several mechanisms - including increased oxidative stress, caspase activation leading to protein breakdown, and activation of the proteasome and calpain proteolytic systems resulting in protein loss. Supinski and colleagues report that the omega- 3 fatty acid eicosapentaenoic acid (EPA) attenuates the loss in diaphragm specific force generation (that is, diaphragm strength) induced by bacterial endotoxin treatment in rats [1].

EPA is found in fish oils, along with its derivative docosahexaenoic acid. In the present study, pure EPA was

*Correspondence: pcc@soton.ac.uk

School of Medicine, University of Southampton, IDS Building, MP887

Southampton General Hospital, Tremona Road, Southampton SO16 6YD, UK administered orally on two occasions: the first at the same time as endotoxin, and the second 24 hours later (G. Supinski, personal communication). Animals were sacrificed 48 hours after the endotoxin administration. EPA was given at a dose of $1 \mathrm{~g} / \mathrm{kg}$ body weight/day (that is, $2 \mathrm{~g} / \mathrm{kg}$ ). For a $250 \mathrm{~g}$ rat, the EPA dose equates to $0.25 \mathrm{~g} /$ day $(0.5 \mathrm{~g}$ in total). This is similar to the amount of EPA that would be consumed by rats fed on a diet containing 5 to $10 \%$ by weight as fish oil, as is commonly used in experimental studies. On the contrary, the amount of EPA provided here could not be translated directly to humans (70 g/day in a $70 \mathrm{~kg}$ individual) and is greatly in excess of amounts provided to patients receiving artificial nutrition either parenterally or enterally [2].

In this new study, endotoxin decreased diaphragm specific force generation by about $50 \%$, while EPA almost totally prevented this reduction [1]. EPA might attenuate the loss of muscle strength through a variety of actions: EPA has been shown to act as a weak antioxidant [3], to inhibit proteasomes [4,5], to inhibit caspase activation [6] and to reduce inflammation [7]. In the study of Supinksi and colleagues, EPA did not prevent the caspase activation or oxidative stress pathways in the diaphragm but it did reduce calpain activation [1], suggesting a specific effect on this proteolytic pathway. Supinski and colleagues thus report a highly novel effect of EPA (attenuation of endotoxin-induced loss of respiratory muscle strength) and a novel mechanism of action (reduced calpain activation) [1]. The implication of this work is that administration of EPA may be able to decrease the respiratory, and perhaps other, muscle weakness that accompanies critical illness and sepsis.

Oral fish oil provided for a period of time prior to endotoxin administration has been shown to decrease post-endotoxin metabolic perturbations and inflammation, to improve heart and lung function, and to reduce mortality [8]. These studies provide EPA (and docosahexaenoic acid) in advance of endotoxin treatment, which is not likely to be the best model for the clinical situation, and may favour an effect of EPA since it will be incorporated into cells and tissues in advance of the endotoxin stimulus. In Supinski and colleagues' study, 
EPA was administered at the same time as, and following, endotoxin administration, which is closer to the clinical situation [1]. In critically ill patients in the intensive care unit, parenteral fish oil improved lung function and decreased the length of hospital stay [9] while an enteral formula that included fish oil improved lung function [10], reduced requirement for ventilatory support $[10,11]$, reduced risk of new organ failures [10-12], decreased the intensive care unit stay [10] and reduced mortality $[11,12]$ in patients with acute respiratory distress syndrome [10], with acute lung injury [11] or with sepsis [12].

The effect on lung function has been linked to a reduction in inflammation $[9,10,13]$. This latest study, however, suggests that there may be an alternative mechanism: improved (or maintained) diaphragm function [1]. The findings of Supinski and colleagues [1] indicate a rapid effect of EPA on the diaphragm that is consistent with the relatively short period of time required to improve lung function $[9,10]$ and to reduce the need for ventilatory support $[10,11]$ seen in these studies in critically ill patients. These latest observations are of significance. It will be important, however, to identify whether EPA administration at a time after the initial insult (in this case, endotoxin) is also protective, since this would be most relevant to the clinical situation, to identify whether doses relevant to the human clinical situation are effective, to examine whether this effect occurs in patients receiving EPA, and to understand more about the mechanism that underpins this effect.

Abbreviations

EPA, eicosapentaenoic acid.

\section{Competing interests}

The author declares that he has no competing interests.

Published: 23 April 2010

References

1. Supinski GS, Vanags J, Callahan LA: Eicosapentaenoic acid preserves diaphragm force generation following endotoxin administration. Crit Care 2010, 14:R35
2. Calder PC: Rationale and use of $\omega-3$ fatty acids in artificial nutrition. Proc Nutr Soc 2010, in press.

3. Saito M, Kubo K: Relationship between tissue lipid peroxidation and peroxidizability index after alpha-linolenic, eicosapentaenoic, or docosahexaenoic acid intake in rats. Br J Nutr 2003, 89:19-28.

4. Whitehouse AS, Tisdale MJ: Downregulation of ubiquitin-dependent proteolysis by eicosapentaenoic acid in acute starvation. Biochem Biophys Res Commun 2001, 285:598-602.

5. Khal J, Tisdale MJ: Downregulation of muscle protein degradation in sepsis by eicosapentaenoic acid (EPA). Biochem Biophys Res Commun 2008, 375:238-240.

6. Magee P, Pearson S, Allen J: The omega-3 fatty acid, eicosapentaenoic acid (EPA), prevents the damaging effects of tumour necrosis factor (TNF)alpha during murine skeletal muscle cell differentiation. Lipids Health Dis 2008, 7:24.

7. Calder PC: N-3 polyunsaturated fatty acids, inflammation, and inflammatory diseases. Am J Clin Nutr 2006, 83:1505S-1519S.

8. Calder PC: Use of fish oil in parenteral nutrition: rationale and reality. Proc Nutr Soc 2006, 65:264-277.

9. Barbosa VM, Miles EA, Calhau C, Lafuente E, Calder PC: Effects of a fish oil containing lipid emulsion on plasma phospholipid fatty acids, inflammatory markers, and clinical outcomes in septic patients: a randomized, controlled clinical trial. Crit Care 2010, 14:R5.

10. Gadek JE, DeMichele SJ, Karlstad MD, Pacht ER, Donahoe M, Albertson TE, Van Hoozen C, Wennberg AK, Nelson JL, Noursalehi M: Effect of enteral feeding with eicosapentaenoic acid, gamma-linolenic acid, and antioxidants in patients with acute respiratory distress syndrome. Enteral Nutrition in ARDS Study Group. Crit Care Med 1999, 27:1409-1420.

11. Singer $P$, Theilla M, Fisher H, Gibstein L, Grozovski E, Cohen J: Benefit of an enteral diet enriched with eicosapentaenoic acid and gamma-linolenic acid in ventilated patients with acute lung injury. Crit Care Med 2006, 34:1033-1038.

12. Pontes-Arruda A, Aragão AM, Albuquerque JD: Effects of enteral feeding with eicosapentaenoic acid, gamma-linolenic acid, and antioxidants in mechanically ventilated patients with severe sepsis and septic shock. Crit Care Med 2006, 34:2325-2333.

13. Pacht ER, DeMichele SJ, Nelson JL, Hart J, Wennberg AK, Gadek JE: Enteral nutrition with eicosapentaenoic acid, gamma-linolenic acid, and antioxidants reduces alveolar inflammatory mediators and protein influx in patients with acute respiratory distress syndrome. Crit Care Med 2003, 31:491-500. doi:10.1186/cc8951

Cite this article as: Calder PC: A novel effect of eicosapentaenoic acid: improved diaphragm strength in endotoxemia. Critical Care 2010, 14:143. 